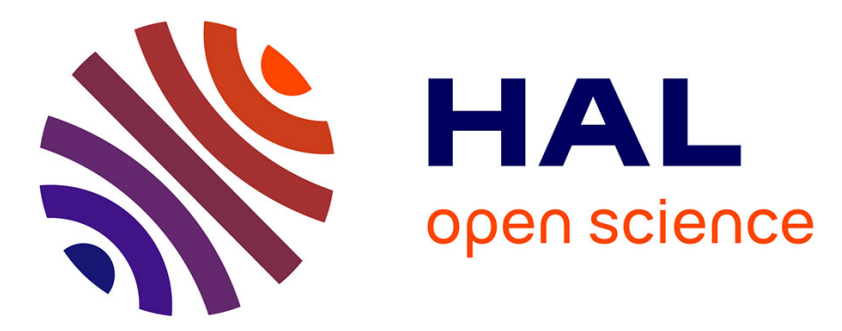

\title{
Development of a split-window algorithm for estimating sea surface temperature from the Chinese Gaofen-5 data
} Yuanyuan Chen, Si-Bo Duan, Jélila Labed, Zhao-Liang Li

\section{To cite this version:}

Yuanyuan Chen, Si-Bo Duan, Jélila Labed, Zhao-Liang Li. Development of a split-window algorithm for estimating sea surface temperature from the Chinese Gaofen-5 data. International Journal of Remote Sensing, 2019, 40 (5-6), pp.1621-1639. 10.1080/01431161.2018.1488295 . hal-02377663

\section{HAL Id: hal-02377663 \\ https://hal.science/hal-02377663}

Submitted on 8 Dec 2020

HAL is a multi-disciplinary open access archive for the deposit and dissemination of scientific research documents, whether they are published or not. The documents may come from teaching and research institutions in France or abroad, or from public or private research centers.
L'archive ouverte pluridisciplinaire HAL, est destinée au dépôt et à la diffusion de documents scientifiques de niveau recherche, publiés ou non, émanant des établissements d'enseignement et de recherche français ou étrangers, des laboratoires publics ou privés. 


\title{
1 Development of a split-window algorithm for estimating \\ 2 sea surface temperature from the Chinese Gaofen-5 data
}

\author{
3 Yuanyuan Chen ${ }^{1,2,3}$, Si-Bo Duan ${ }^{1}$, Jélila Labed ${ }^{3}$ and Zhao-Liang \\ $4 \mathrm{Li}^{1,3, *}$ \\ $5 \quad{ }^{1}$ Key Laboratory of Agricultural Remote Sensing, Ministry of \\ 6 Agriculture/Institute of Agricultural Resources and Regional Planning, \\ 7 Chinese Academy of Agricultural Sciences, Beijing, 100081, China \\ $8 \quad{ }^{2}$ Key Laboratory of Cultivated Land Use, Ministry of Agriculture, P. R. \\ 9 China; Chinese Academy of Agricultural Engineering, Beijing, 100121, China \\ $10{ }^{3}$ ICube, UdS, CNRS (UMR7357), 300 Bld Sebastien Brant, CS10413, 67412, \\ 11 Illkirch, France \\ 12 *lizhaoliang@caas.cn \\ 13
}

14

15

16

17

18

19

20

21

22

23

24

25

26

27 


\title{
Development of a split-window algorithm for estimating sea surface temperature from the Chinese Gaofen-5 data
}

\begin{abstract}
Sea surface temperature (SST) is an essential climate variable that can be used to assess climate change. One kind of method commonly used to estimate SST based on remote sensing measurements is the split-window (SW) algorithm. However, the derivation of the linear SW algorithm does not appear to reflect reality because some assumptions and approximations were used. Moreover, the quadratic SW equation cannot be interpreted theoretically although it maintains the structure of the linear SW equation. The Gaofen-5 (GF-5) satellite launch is planned for 2017. Focusing on exploring the mechanism of the SW algorithm using GF-5 data, this study investigated the assumptions and approximations used to derive the linear SW technique. Two revised equations of these assumptions and approximations were developed. Combining the revised equations, a nonlinear SW algorithm was obtained that could be simplified to the quadratic equation. Compared with previous research, this study focuses more on the theoretical interpretation and improves our understanding of the semiempirical quadratic SW equation. The matchup dataset produced by the European Organization for the Exploitation of Meteorological Satellites (EUMETSAT) Ocean and Sea Ice Satellite Application Facility (OSI$\mathrm{SAF}$ ) was used to validate the quadratic SW algorithm. A bias of -0.05 $\mathrm{K}$ and a RMSE of $0.53 \mathrm{~K}$ were obtained.
\end{abstract}

Keywords: Sea surface temperature; Split-window; Revision; GF-5; Thermal infrared

\section{Introduction}

As an important parameter in the exchange of energy between the ocean and the atmosphere, the sea surface temperature (SST) reflects both oceanic and 
atmospheric variability on multiple temporal and spatial scales (Fisher 1958; Liu and Minnett 2015). High-quality SST datasets are needed for many applications, such as numerical weather prediction, ocean forecasting, and climate change assessment (Pinardi et al. 2003; Barnett et al. 1993; Chelton and Wentz 2005; Donlon et al. 2007). Knowledge of the distribution of SST is also useful for locating various species of fish (Simpson 1994). Such investigations can be satisfied using satellite remote sensing data. However, accurate determination of SST from satellite data is a difficult task because the at-sensor measured radiances include the atmospheric absorption and emission (Liu et al. 2013). Thus, removal of the atmospheric effects is a key step in the accurate retrieval of SST from remotely sensed data.

Despite the problem of atmospheric effects, retrieval of SST information from space using thermal infrared (TIR) data began in 1970. Anding and Kauth (1970) first demonstrated that the atmospheric effects can be almost compensated for by simultaneously using the radiometric measurements in two properly selected TIR bands. Prabhakara et al. (1974) first suggested the general method of estimating SST from two TIR channel measurements. Therefore, the split-window (SW) technique for estimating SST was derived based on the previous works, with the general idea that the atmospheric effects are proportional to the difference between the at-sensor radiances measured simultaneously in two TIR channels (McMillin 1975; Ulivieri et al. 1994; Coll and Caselles 1997; Rozenstein et al. 2014). For 
78 nighttime retrieval, the channel near $3.7 \mu \mathrm{m}$ is often used to improve the

79 accuracy of SST retrieval because it's a more transparent band, compared with

80 the bands centered at 11 and $12 \mu \mathrm{m}$ (Barton 1983). However, there is significant

81 solar radiation at this wavelength that restricts the channel to be used for

82 daytime SST retrieval (McClain, Pichel, and Walton 1985; Petrenko et al. 2014).

83 Since then, a variety of methods based on the SW technique have been

84 developed and improved to retrieve SST and LST (land surface temperature)

85 (McClain, Pichel, and Walton 1985; Becker and Li 1990; Sobrino, Li, and Stoll

1993; Niclòs et al. 2007; Qian et al. 2016).

In the derivation of the $\mathrm{SW}$ technique, some assumptions and approximations were made to obtain the SST. One assumption is the first-order Taylor approximation of the Planck function (Prabhakara, Dalu, and Kunde 1974; Becker 1987). Another assumption is that the atmospheric equivalent temperatures in the two adjacent TIR channels were the same $\left(T_{a i}=T_{a j}\right)$ (McMillin 1975; Sobrino, Coll, and Caselles 1991). Notably, there are certain restrictions for these assumptions. As demonstrated in the literature (Sobrino, Coll, and Caselles 1991; Becker 1987), the linear approximation of the Planck function is generally accurate under the condition that $T$ and $T_{i}$ are close to each other ( $T$ represents the atmospheric equivalent temperature or surface temperature and $T_{i}$ is the brightness temperature measured by the satellite). However, it is difficult to meet this condition due to the strong variability of global atmospheric conditions. In addition, the hypothesis $T_{a i}=T_{a j}$ does not 
appear to reflect reality. Therefore, these assumptions and approximations must

101 be re-examined.

102 The Gaofen-5 (GF-5) satellite is expected to be launched in 2017. An

103 advantage of the multiple spectral-imager (MSI) onboard GF-5 satellite is the

104 high spatial resolution (40 meters for TIR channels). As a result, applications

105 of the TIR data from GF-5 are different from those of other sensors with coarser

106 spatial resolutions. For example, the high resolution SST data of GF-5 can be

107 used to monitor the thermal pollution produced by the nuclear power. Thus,

108 there is an urgent need to develop an algorithm that is suitable for retrieving

109 SST from GF-5/TIR data. In this paper, the investigation of the following

110 assumptions and approximations: 1) the linearization of the Planck function and

111 2) the atmospheric equivalent temperatures in two TIR channels, which were

112 assumed to be the same was undertaken based on the Chinese GF-5 data. We

113 aim to explore the mechanism of the SW algorithm further through revising

114 these assumptions and approximations. The paper is organized as follows:

115 Section 2 describes the data used in this study. The theoretical revision and

116 derivation of the SW technique, including revision of the linearization of the

117 Planck function, revision of the $T_{a i}=T_{a j}$ hypothesis and analysis of the

118 developed SW algorithm, are documented in Section 3. The effect of instrument

119 noise on SST retrieval and the algorithm validation are described in Section 4.

120 The discussion is given in Section 5. Finally, Section 6 presents the conclusions. 


\section{Data}

122

123 With the launch of the China High-resolution Earth Observation System

124 (CHEOS), China has entered a new era of high resolution operations. GF-5 is

125 the fifth satellite in a series of CHEOS, scheduled to be launched in 2017. One

126 of the major sensors onboard the GF-5 satellite is the multiple spectral-imager

127 (MSI) that includes 13 channels covering the spectral range from visible to TIR

128 and observes the earth almost at nadir. The channels centered at $10.8 \mu \mathrm{m}$ and

$12911.95 \mu \mathrm{m}$ are two TIR channels (labeled $\mathrm{CH}_{10.8}$ and $\mathrm{CH}_{11.95}$, respectively,

130 hereafter) suitable for SW method, with a spatial resolution of 40 meters. The

131 spectral response functions of $\mathrm{CH}_{10.8}$ and $\mathrm{CH}_{11.95}$ are shown in Figure 1.

\subsection{Matchup data set}

133 To assess the performance of the developed algorithm, Matchup dataset (MDS)

134 produced by the European Organization for the Exploitation of Meteorological

135 Satellites (EUMETSAT) Ocean and Sea-Ice Satellite Application Facility

136 (OSI-SAF) was collected. MDS was provided in NetCDF format, containing

137 the fields of latitude, longitude, viewing zenith angle (VZA), acquisition time,

138 AVHRR at-sensor brightness temperatures, in situ SSTs, etc. AVHRR

139 brightness temperatures are coincident in time and space with the in situ SSTs.

140 From Figure 1, which also displays the spectral response functions of AVHRR 
141 SW channels, we can see that the spectral configuration of GF-5/MSI and

142 AVHRR SW channels is similar. Considering the lack of available GF-5 data

143 at present, the "true" GF-5 brightness temperature can be got from the AVHRR

144 measurements based on the relationship built by the simulated data for the

145 purpose of algorithm validation. The in situ SSTs recorded by drifting buoys

146 were collected from the Global Telecommunication System (GTS) with an

147 AVHRR pixel. Figure 2 shows the location distribution of in situ SSTs, 148 indicating the almost global coverage of in situ measurement.

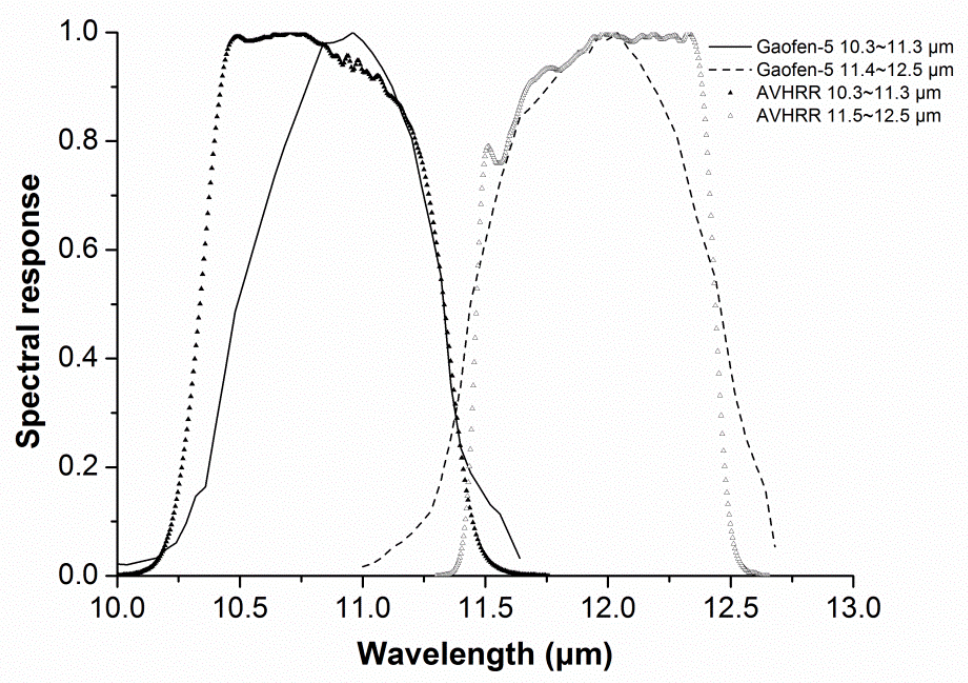

149

150 Figure 1. Spectral response functions for Gaofen-5 and AVHRR split-window 151 channels. 


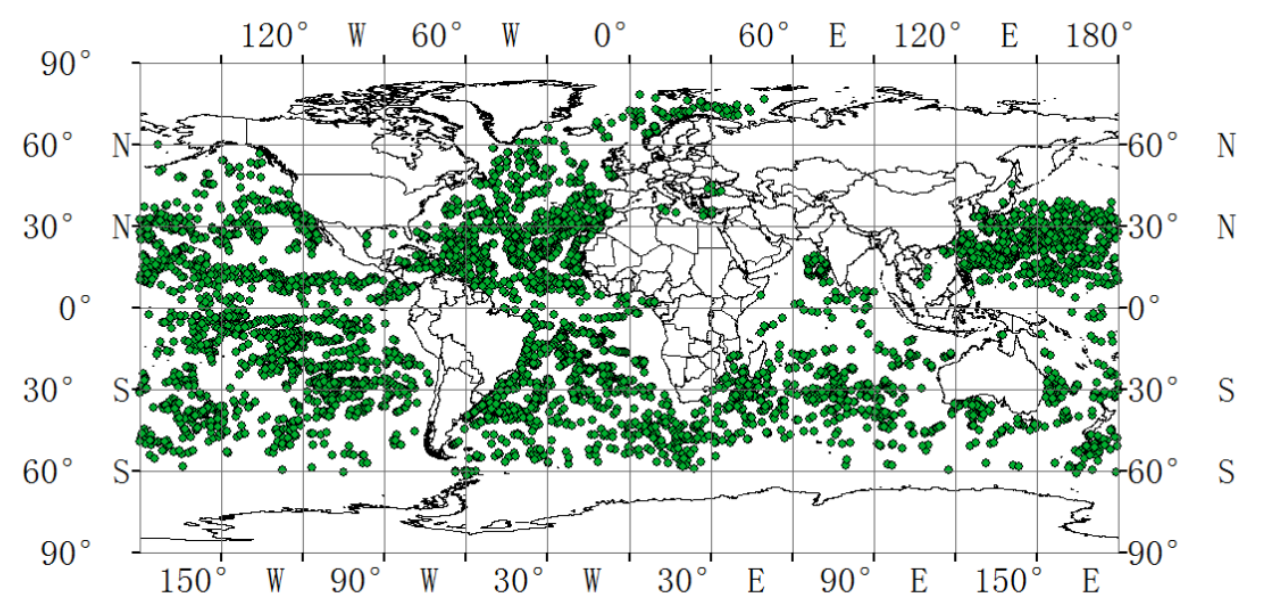

152

153 Figure 2. Distribution of in situ sea surface temperatures on the global ocean.

154

155

156

157

158

159

160

$161 \mathrm{~g} / \mathrm{cm}^{2}$, it is reasonable to select different atmospheric profiles according to well-

162 distributed values of WVC. Figure 3 shows the 104 atmospheric profiles

163 selected, with the atmospheric temperature in the lowest layer $\left(\mathrm{T}_{0}\right)$ varying from

$164232.25 \mathrm{~K}$ to $303.41 \mathrm{~K}$ and the WVC from $0.09 \mathrm{~g} / \mathrm{cm}^{2}$ to $5.69 \mathrm{~g} / \mathrm{cm}^{2}$, which

165 constructed a robust database capable of representing global atmospheric

166 conditions with a moderate number of samples and a nearly uniform WVC 
167 distribution. Eighty-one profiles (referred to as TIGR_81) were used for

168 developing the SST retrieval algorithm and twenty-three profiles (referred to as

169 TIGR_23) were used for validation.

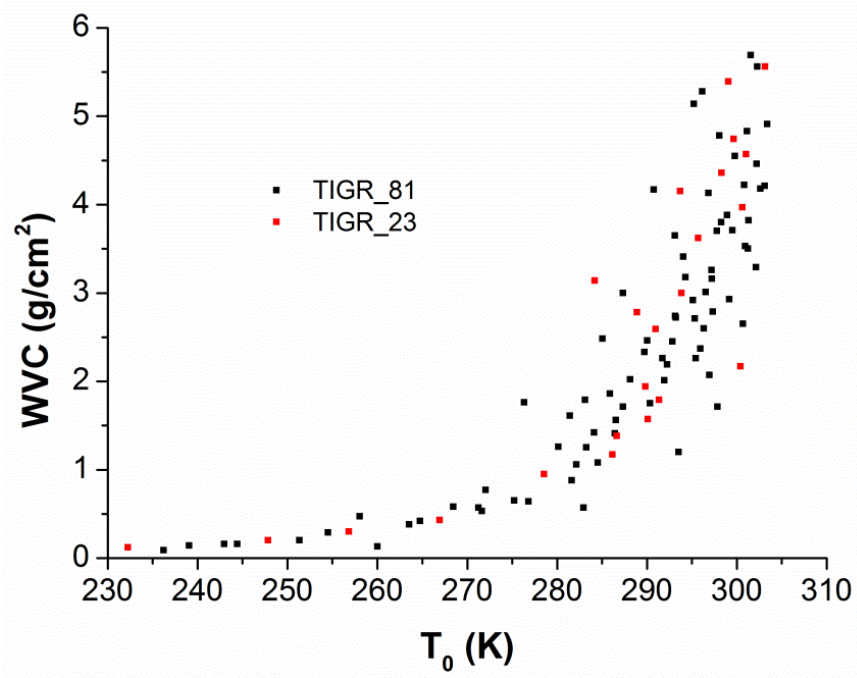

170

171 Figure 3. Plot of the total water vapor content (WVC) as a function of 172 atmospheric temperature in the lowest layer $\left(\mathrm{T}_{0}\right)$ for selected atmospheres. 173 TIGR_81 was used for algorithm development (black points) and TIGR_23 174 (red points) for algorithm validation

\subsection{Generation of the simulated database}

176 To obtain an appropriate simulated database for developing a SST retrieval 177 algorithm for GF-5 TIR data, the atmospheric radiative transfer model 178 MODTRAN (Berk et al. 1999) was used to simulate the spectral atmospheric 179 parameters of spectral transmittance $\tau \lambda$, spectral atmospheric upwelling 180 radiance $R_{\text {atm_ } \lambda}^{\uparrow}$ and spectral atmospheric downwelling $R_{\text {atm } \_ \text {. }}^{\downarrow}$. The channel181 effective atmospheric parameters $\tau_{i}, R_{a t m_{-} i}^{\uparrow}$ and $R_{a t m_{-} i}^{\downarrow}$ can be obtained by 
182 integrating these spectral variables with spectral response functions in $\mathrm{CH}_{10.8}$

183 and $\mathrm{CH}_{11.95}$. The channel brightness temperature $T_{i}$ at the top of the atmosphere

184 (TOA) can then be determined according to the radiative transfer equation

185 (RTE) (Coll and Caselles 1994; Niclòs et al. 2007) by inverting the Planck

186 function in combination with a wide range of SSTs, considering the VZA of $0^{\circ}$.

187 For a more realistic simulation, the SSTs reasonably vary with $\mathrm{T}_{0}$. Specifically,

188 five SSTs $\left(\mathrm{T}_{0}-5 \mathrm{~K}, \mathrm{~T}_{0}-2 \mathrm{~K}, \mathrm{~T}_{0} \mathrm{~K}, \mathrm{~T}_{0}+2 \mathrm{~K}\right.$ and $\left.\mathrm{T}_{0}+5 \mathrm{~K}\right)$ were considered in

189 this study. All of the data were obtained considering the emissivity to be equal

190 to one because the ocean surface radiates almost as a blackbody at infrared

191 wavelengths (McClain, Pichel, and Walton 1985). A flow chart of generation

192 of the simulated data is presented in Figure 4. 


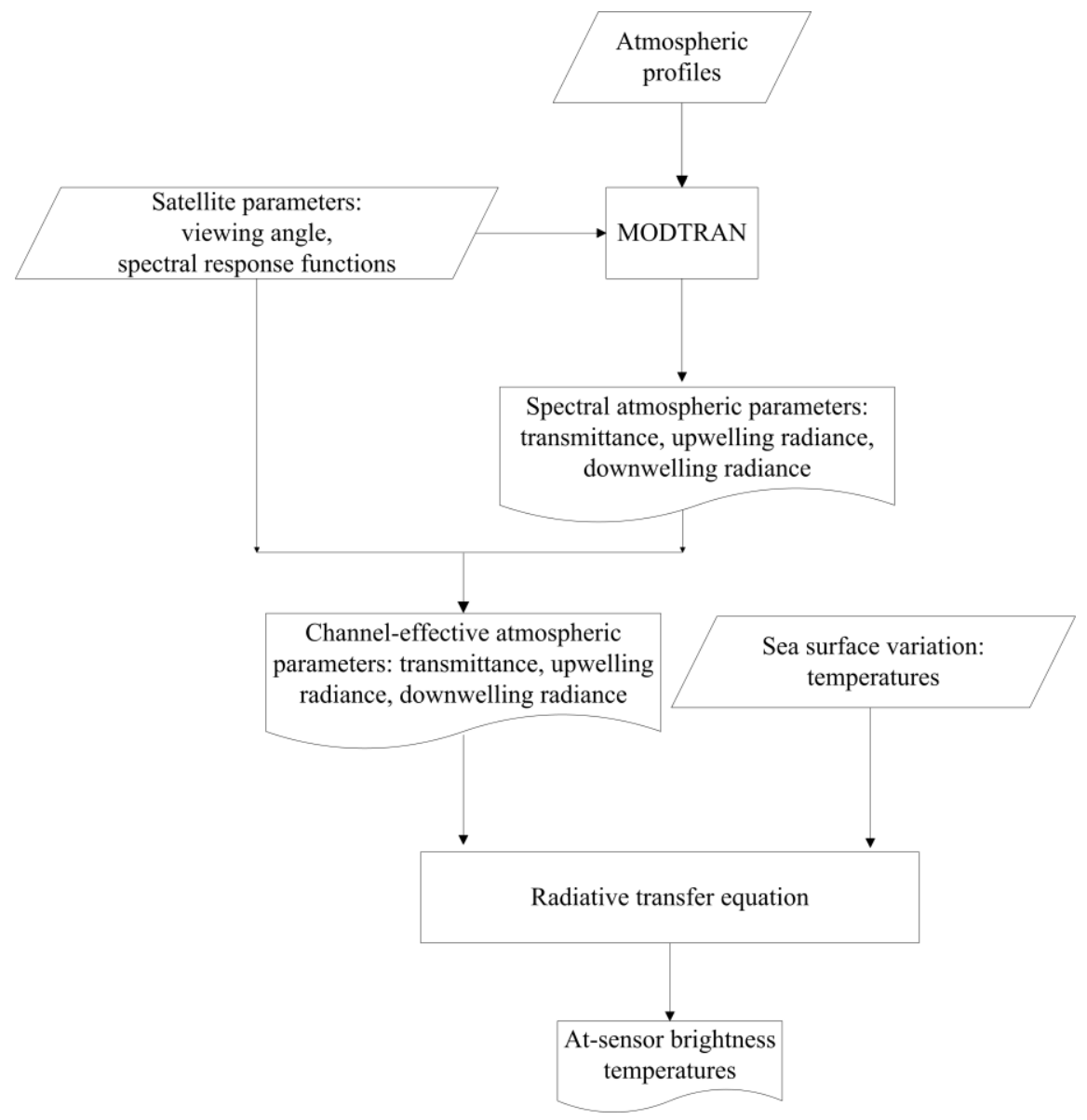

Figure 4. The procedure of generating the simulated data.

\section{3. Method of revising the linear SW algorithm}

196 The theoretical basis for the SST retrieval algorithm relies on the RTE.

197 Assuming that: 1) the first-order Taylor approximation of the Planck function

198 was used and 2) the atmospheric equivalent temperatures in two TIR channels

199 were equal $\left(T_{a i}=T_{a j}\right)$, a typical linear SW algorithm (Sobrino, Li, and Stoll

200 1993; McClain, Pichel, and Walton 1985; Barton 1995; Kilpatrick, Podestfi, 201 and Evans 2001) can be obtained: 
203 where $T_{s}$ is the sea surface temperature (i.e., SST; hereafter, SST is used 204 interchangeably with $T_{s}$ ), $T_{i}$ and $T_{j}$ are the brightness temperatures in channels $205 i$ and $j$ at the TOA, and $A$ is the coefficient defined by $A=\left(1-\tau_{i}\right) /\left(\tau_{i}-\tau_{j}\right)$ in 206 which $\tau_{i}$ and $\tau_{j}$ are the transmittances through the atmosphere from the surface 207 to the satellite in channels $i$ and $j$. Eq. (1) indicates that a linear relationship 208 exists between $T_{s}-T_{i}$ and $T_{i}-T_{j}$. However, an empirical quadratic relationship 209 was found when relating $T_{s}-T_{i}$ to $T_{i}-T_{j}$. Coll et al. (1994) proposed a quadratic 210 SW equation but no physical interpretation. In the next section, we will

211 investigate the derivation of the quadratic SW equation by re-examining the 212 two assumptions and approximations mentioned above.

213 215

\subsection{Revision of the linearization of the Planck function}

Based on the RTE, Eq. (2) can be obtained by using Taylor's expansion of the Planck function,

$$
T_{i}=T_{a i}+\tau_{i}\left(T_{s}-T_{a i}\right)+\Delta T_{i}
$$

where $\triangle T_{i}$ is the error in $T_{i}$ caused by linearizing the Planck function. In the published literature, $\triangle T_{i}$ is small and always neglected (McClain, Pichel, and Walton 1985; Walton et al. 1998; Prabhakara, Dalu, and Kunde 1974). Using the simulated data, the calculated results of $\triangle T_{i}$ for $\mathrm{CH}_{10.8}$ and $\mathrm{CH}_{11.95}$ by Eq. 
221 (2) are shown in Figure 5 (a) and (b). It can be observed that a RMSE of 0.10

$222 \mathrm{~K}$ and a bias of $0.07 \mathrm{~K}$ were obtained for $\mathrm{CH}_{10.8}$, and those of $\mathrm{CH}_{11.95}$ were 0.11

$223 \mathrm{~K}$ and $0.08 \mathrm{~K}$, respectively. Writing Eq. (2) for two channels, one can obtain

224 Eq. (3),

225

$$
T_{s}=T_{i}+A\left(T_{i}-T_{j}\right)+\Delta T_{s 1}+\Delta T_{s 2}
$$

226 where $\triangle T_{s 1}=-\triangle T_{i}-A\left(\triangle T_{i}-\triangle T_{j}\right)$ with the same $A$ as in Eq. (1), $\triangle T_{s 2}=A a\left(\mathrm{~T}_{a i}\right.$

$\left.227-\mathrm{T}_{a j}\right)$ with $A_{a}=-\left(1-\tau_{i}\right)\left(1-\tau_{j}\right) /\left(\tau_{i}-\tau_{j}\right)$. We can see that $\Delta T_{s 1}$ is the error of $T_{s}$

228 retrieval caused by linearizing the Planck function and $\Delta T_{s 2}$, which will be

229 presented in Section 3.2, is the influence of the hypothesis $T_{a i}=T_{a j}$ on $T_{s}$

230 retrieval. Figure 5 (c) displays the results of $\Delta T_{s 1}$, which is within the range of

$231-0.4 \sim 0.5 \mathrm{~K}$. The negative bias $(-0.06 \mathrm{~K})$ of $\Delta T_{s 1}$ indicates that the surface

232 temperature was overestimated due to the linearization of the Planck function, 233 with $\mathrm{RMSE}=0.10 \mathrm{~K}$. 
236

237

238

239

240

241

242

243

244

245

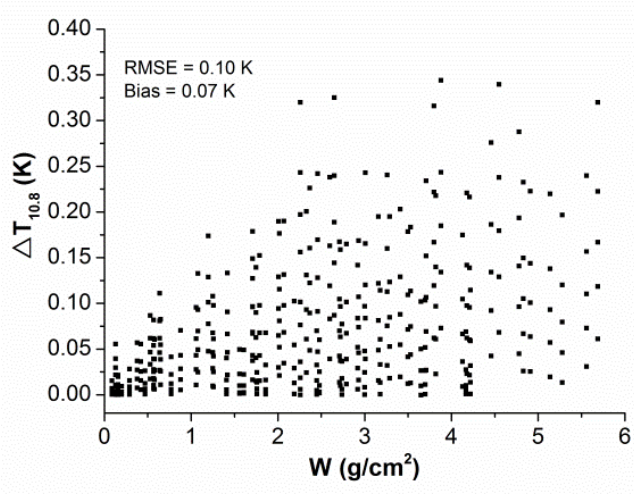

(a)

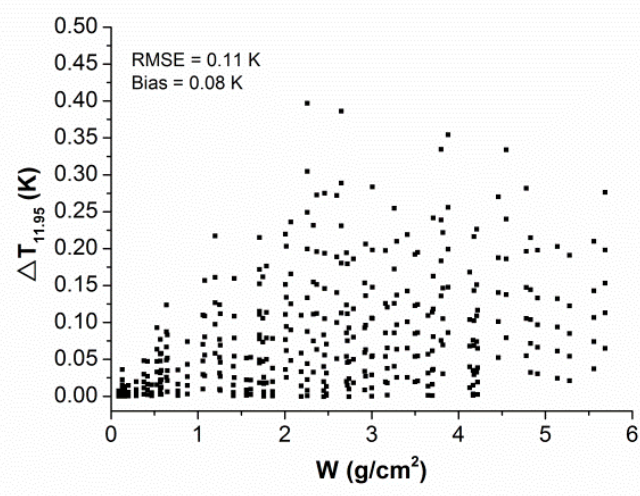

(b)

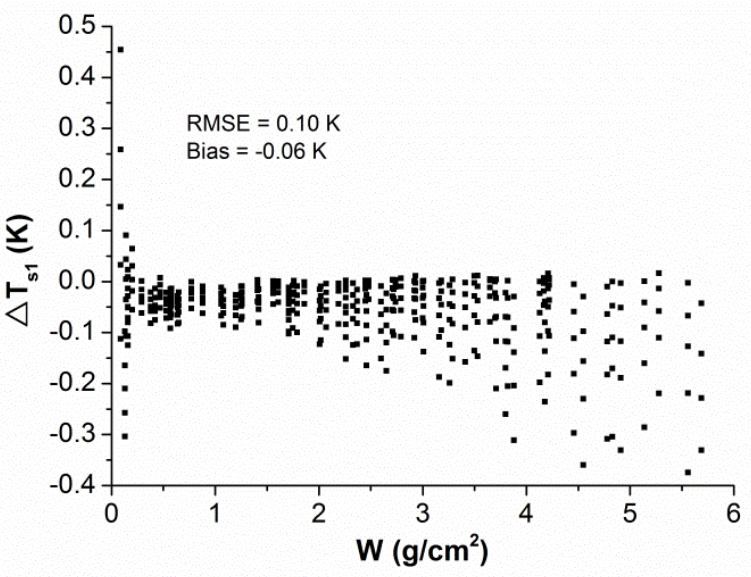

(c)

Figure 5. The error caused by the linearization of the Planck function for channels with central wavelengths of (a) $10.8 \mu \mathrm{m}$, (b) $11.95 \mu \mathrm{m}$ and (c) for SST. To revise the error caused by the linearization of the Planck function, the second-order derivative of Taylor's expansion was considered. Based on the RTE, $\triangle T_{i}$ in Eq. (2) can be rewritten as the following expression:

$$
\Delta T_{i}=\frac{\frac{1}{2}\left(\frac{\partial^{2} B_{i}(T)}{\partial T^{2}}\right)_{T_{i}}\left[\left(1-\tau_{i}\right)\left(T_{a i}-T_{i}\right)^{2}+\tau_{i}\left(T_{s}-T_{i}\right)^{2}\right]}{\left(\frac{\partial B_{i}(T)}{\partial T}\right)_{T_{i}}}
$$


246 where $\left(\frac{\partial B_{i}(T)}{\partial T}\right)_{T_{i}}$ and $\left(\frac{\partial^{2} B_{i}(T)}{\partial T^{2}}\right)_{T_{i}}$ are the first-order and second-order 247 derivatives of the Planck function at temperature $T_{i}$, respectively. Eq. (4) shows 248 that $\Delta T_{i}$ is described by a complex expression. Parameterization of Eq. (4) is 249 necessary. Considering the simplified case of Eq. (2) in which $\Delta T_{i}$ was 250 regarded as zero, Eq. (2) can also be rewritten as:

$$
\left(1-\tau_{i}\right)\left(T_{i}-T_{a i}\right)=\tau_{i}\left(T_{s}-T_{i}\right)
$$

252 Putting the square on both sides of Eq. (5), one can obtain Eq. (6) by simple 253 mathematical manipulation,

$$
\left(1-\tau_{i}\right)\left(T_{i}-T_{a i}\right)^{2}=\tau_{i}\left(T_{s}-T_{i}\right)^{2} \frac{\tau_{i}}{1-\tau_{i}}
$$

255 In addition, using the approximation of the Planck function in the work of Price 256 (1984),

$$
B_{i}\left(T_{i}\right)=a_{i} T_{i}^{n_{i}}
$$

258 where $a_{i}$ and $n_{i}$ are constants in a given channel, Eq. (8) can be obtained:

$$
\left(\frac{\partial^{2} B_{i}(T)}{\partial T^{2}}\right)_{T_{i}} /\left(\frac{\partial B_{i}(T)}{\partial T}\right)_{T_{i}}=\frac{n_{i}-1}{T_{i}}
$$


260 Combining Eqs. (6) and (8), $\triangle T_{i}$ can be parameterized as $\frac{1}{2}\left(n_{i}-1\right) \frac{\left(T_{s}-T_{i}\right)^{2} \tau_{i}}{T_{i}\left(1-\tau_{i}\right)}$.

261 As shown in Figure 6, there is a strong dependence between $\triangle T_{i}$ and $262 \frac{\left(T_{s}-T_{i}\right)^{2} \tau_{i}}{T_{i}\left(1-\tau_{i}\right)}$, with sufficient accuracy of $T_{i}$ (RMSE lower than $\left.0.01 \mathrm{~K}\right)$ for both

263 channels. Based on Figure $6, \triangle T_{i}$ is rewritten as:

$$
\Delta T_{i}=\alpha_{i} \frac{\left(T_{s}-T_{i}\right)^{2} \tau_{i}}{T_{i}\left(1-\tau_{i}\right)}
$$

265 where $\alpha_{i}$ is the regression coefficient, which is 1.40 for $\mathrm{CH}_{10.8}$ and 1.21 for $266 \mathrm{CH}_{11.95}$

267

268

269

270

271

272

273

274

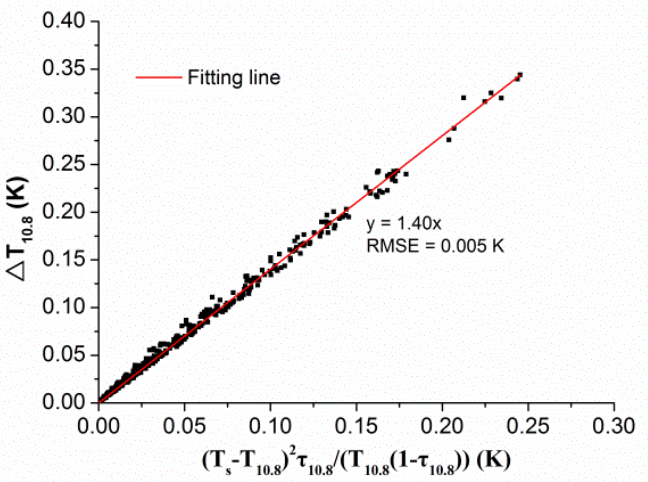

(a)

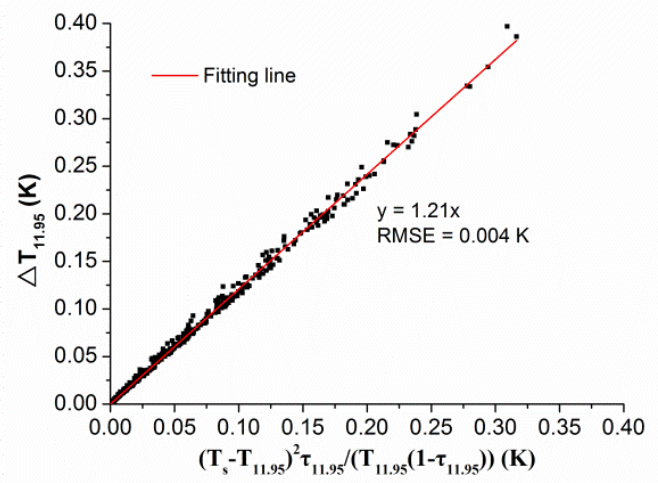

(b)

Figure 6. $\triangle T_{i}$ versus $\left(T_{s}-T_{i}\right)^{2} \tau_{i} /\left(T_{i}\left(1-\tau_{i}\right)\right)$ for Gaofen-5 TIR channels centered at (a) $10.8 \mu \mathrm{m}$ and (b) $11.95 \mu \mathrm{m}$. Here, $T_{s}$ is the surface temperature, $T_{i}$ is the simulated brightness temperature, $\tau_{i}$ is the transmittance and $\triangle T_{i}$ is the difference between the simulated and estimated brightness temperatures from Eq. (2).

\subsection{Revision of the $T_{a i}=T_{a j}$ hypothesis}


275 If the hypothesis of $T_{a i}=T_{a j}$ is used for the $T_{s}$ retrieval, $\Delta T_{s 2}$ in Eq. (3) is 0 .

276 However, according to the calculated $T_{a 10.8}$ and $T_{a 11.95}$ using the thermal-path

277 atmospheric upwelling radiance generated from the simulation, $\Delta T_{s 2}$ ranges

278 from about $-6 \sim 2 \mathrm{~K}$, as seen in Figure 7. It can be concluded that use of the $T_{a i}$

$279=T_{a j}$ hypothesis can lead to large error in $T_{s}$ retrieval, with the RMSE of 1.74

$280 \mathrm{~K}$ and bias of $-0.88 \mathrm{~K}$.

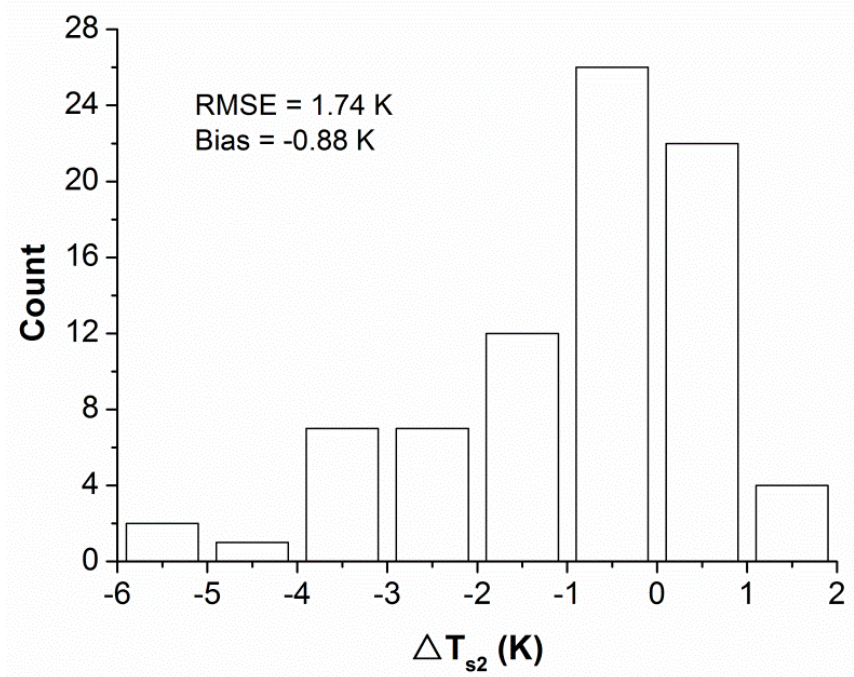

282 Figure 7. The error caused by the hypothesis of $T_{a 10.8}=T_{a 11.95}$ for SST retrieval. 283 Here, $T_{a 10.8}$ and $T_{a 11.95}$ are the atmospheric equivalent temperatures in Gaofen2845 SW channels.

285 Notably, the discrepancy between $T_{a i}$ and $T_{a j}$ must be taken into account 286 in SST retrieval from satellite observations (Franqois and Ott1é 1996). From 287 Figure 8, it can be observed that 1) there is a discrepancy between $T_{a 10.8}$ and $288 T_{a 11.95}$ for GF-5 data, with $T_{a 11.95}>T_{a 10.8}$ for low $T_{a 10.8}$ and $T_{a 11.95}<T_{a 10.8}$ for high $289 T_{a 10.8}$. The maximum difference between $T_{a 10.8}$ and $T_{a 11.95}$ is almost $4 \mathrm{~K} ; 2$ ) $290 T_{a 11.95}$ and $T_{a 10.8}$ are approximately equal only in a small range of atmospheric 
291 conditions, at approximately $T_{a 10.8}$ between $275-285 \mathrm{~K}$; 3) there is a linear 292 dependence between $T_{a 10.8}$ and $T_{a 11.95}$,

$$
T_{a 11.95}=a T_{a 10.8}+b
$$

294 where $a=0.9172$ and $b=23.00$, with RMSE $=0.50 \mathrm{~K}$. Using this linear 295 relationship, the SST residual calculated by Eq. (3) is shown in Figure 9. 296 Compared with the result caused by the hypothesis of $T_{a i}=T_{a j}$, the RMSE is 297 changed to $0.62 \mathrm{~K}$ and the bias is changed to $-0.10 \mathrm{~K}$.

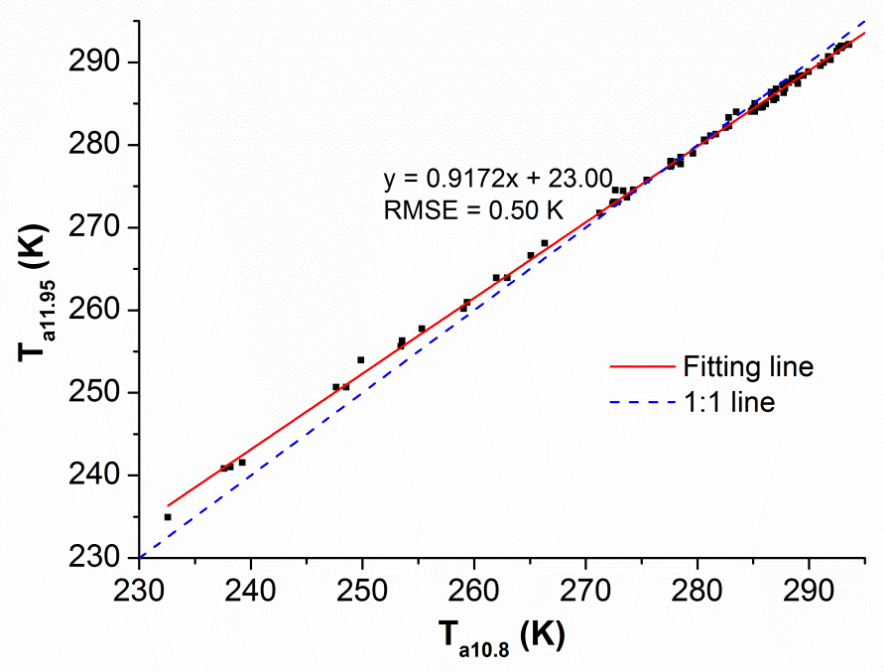

299 Figure 8. The relationship between atmospheric equivalent temperatures in two 300 Gaofen-5 TIR channels (labeled $T_{a 10.8}$ and $\left.T_{a 11.95}\right)$. 


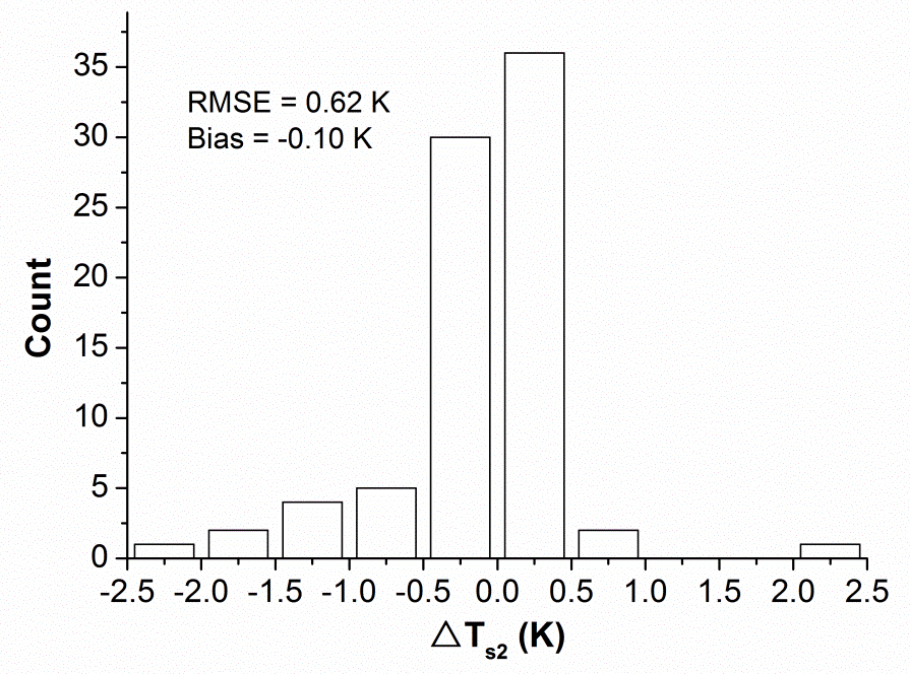

301

302 Figure 9. The SST residual obtained by Eq. (3) when the linear dependence of 303 the atmospheric equivalent temperatures in two TIR channels was used.

304 Combining Eq. (9) and Eq. (10), the SST can be obtained by writing Eq.

305 (2) for two SW channels,

$$
S S T=M T_{10.8}+N T_{11.95}
$$

307 where $M=\frac{A_{4}}{2\left(A_{1}-A_{2} \frac{T_{10.8}}{T_{11.95}}\right)}, N=\frac{\sqrt{A_{4}^{2}+4\left(\frac{A_{1}}{T_{10.8}}-\frac{A_{2}}{T_{11.95}}\right)\left(A_{5} T_{10.8}+A_{6} T_{11.95}+A_{3}\right)}}{2\left(A_{1} \frac{T_{11.95}}{T_{10.8}}-A_{2}\right)}$,

308 with

$309 \quad A_{1}=\frac{a \alpha_{10.8}\left(1-\tau_{11.95}\right) \tau_{10.8}}{1-\tau_{10.8}}, A_{2}=\frac{\alpha_{11.95}\left(1-\tau_{10.8}\right) \tau_{11.95}}{1-\tau_{11.95}}, A_{3}=b\left(1-\tau_{10.8}\right)\left(1-\tau_{11.95}\right)$,

310

$A_{4}=2\left(A_{1}-A_{2}\right)-a\left(1-\tau_{11.95}\right) \tau_{10.8}+\left(1-\tau_{10.8}\right) \tau_{11.95} \quad, \quad A_{5}=-A_{1}+a\left(1-\tau_{11.95}\right)$,

$311 \quad A_{6}=A_{2}-\left(1-\tau_{10.8}\right)$ 
313 Equation (11) is complex, requiring analysis and simplification. According to

314 the simulated data, $M$ ranged from $0.9620 \sim 0.9941$ and $N$ from $0.0328 \sim 0.0394$.

315 Taking the value of $M$ approximately close to one, Eq. (11) can be rewritten as:

316

$$
S S T-T_{10.8}=(M-1)\left(T_{10.8}-T_{11.95}\right)+(M-1+N) T_{11.95}
$$

317 Since $(M-1)$ is close to 0 , the first term of Eq. (12) (i.e., $(M-1)\left(T_{10.8}-T_{11.95}\right)$ )

318 is small even if multiplied by the maximum of $\left(T_{10.8}-T_{11.95}\right)$ (approximately 4

$319 \mathrm{~K})$. In contrast to the small value of the first term, the second term (i.e., $(M-1$

$320+N) T_{11.95}$ ) makes the main contribution to Eq. (12) (see Figure 10), because of 321 the large value of $T_{11.95}$. Taking the structure of the $\mathrm{SW}$ algorithm into 322 consideration, $(M-1+N) T_{11.95}$ should be the function of $\left(T_{10.8}-T_{11.95}\right)$.

323 Therefore, the relationship between $(M-1+N) T_{11.95}$ and $\left(T_{10.8}-T_{11.95}\right)$ was 324 investigated further. As shown in Figure 11, $(M-1+N) T_{11.95}$ can be 325 parameterized using $\left(T_{10.8}-T_{11.95}\right)$, with $\mathrm{RMSE}=0.30 \mathrm{~K}$.

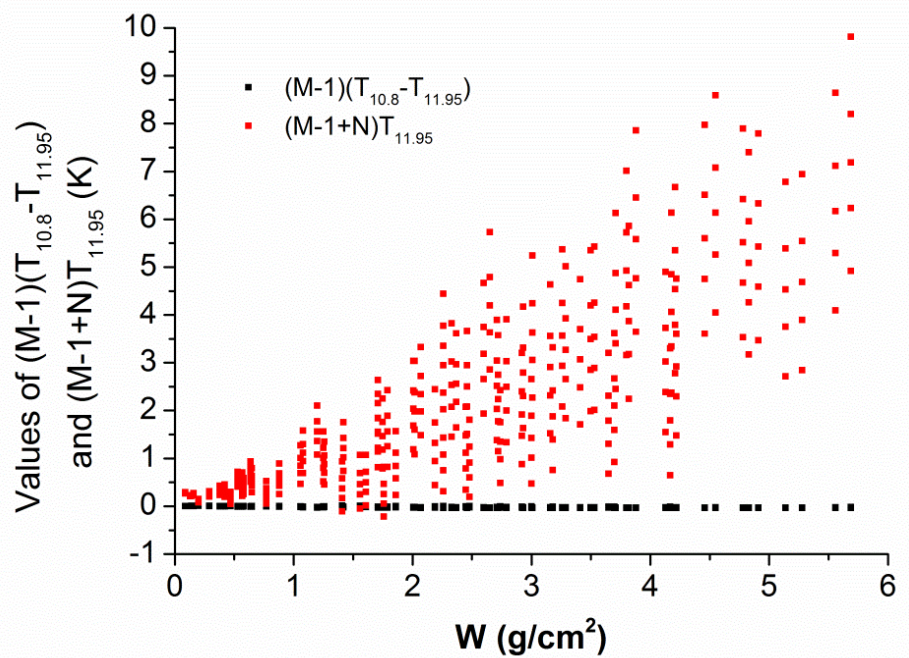


327 Figure 10. Values of $(M-1)\left(T_{10.8}-T_{11.95}\right)$ and $(M-1+N) T_{11.95}$ in Eq. (12)

328 versus the atmospheric water vapor content (WVC).

329

330 Figure 11. The relationship between $(M-1+N) T_{11.95}$ in Eq. (12) and the 331 difference of the brightness temperatures in SW channels $\left(T_{10.8}-T_{11.95}\right)$.

334 where $A, B$ and $C$ are the coefficients. Using the least-square fitting method, the 335 coefficients $A=0.4253, B=1.123$ and $C=0.28$ were obtained using the 336 simulated data, with RMSE $=0.30 \mathrm{~K}$. Figure 12 shows the histogram of the 337 difference between the actual SST and that obtained by Eq. (13). 


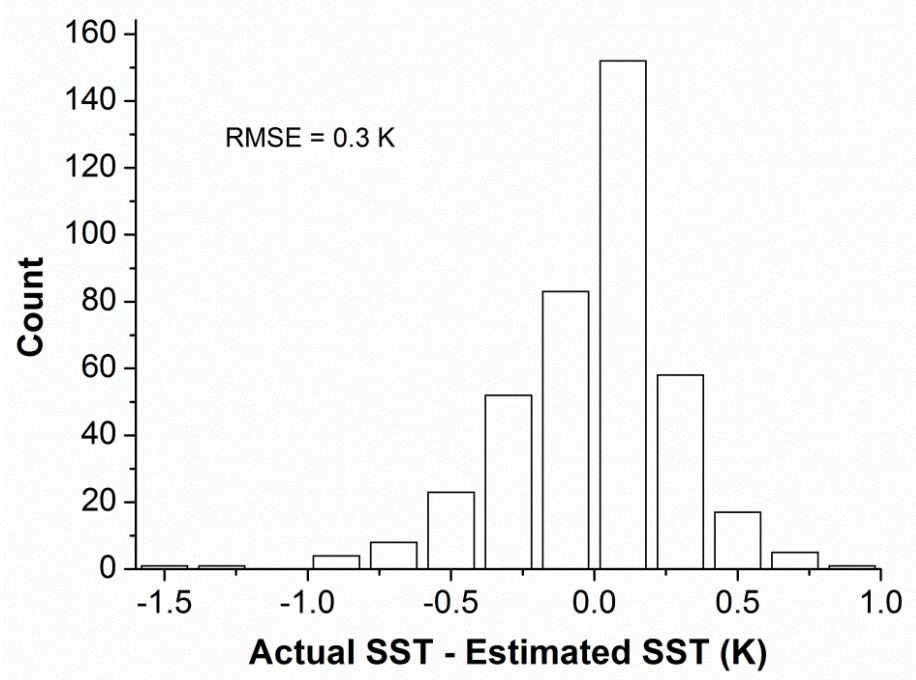

338

Figure 12. Histogram of the differences between the actual and estimated SSTs 340 using Eq. (13).

\section{Error analysis and validation}

\subsection{Error of the instrument noise}

344 The accuracy of the estimated SST will essentially depend on the radiometric

345 performance of the instrument. The noise equivalent differential temperature $346(\mathrm{NE} \Delta \mathrm{T})$ in infrared channels is designed to be $0.2 \mathrm{~K}$ for GF-5 TIR data. To 347 evaluate the performance of the quadratic algorithm in this study, a simulation 348 of the effect of satellite noise was performed using a set of randomly generated 349 signal level perturbations with errors of $0.1 \mathrm{~K}, 0.2 \mathrm{~K}$ and $0.3 \mathrm{~K}$ for both channels. 350 The RMSEs between the true SSTs and those retrieved from the noise-added 351 brightness temperatures are $0.49 \mathrm{~K}, 0.82 \mathrm{~K}$ and $1.20 \mathrm{~K}$ for $\mathrm{NE} \Delta \mathrm{T}=0.1 \mathrm{~K}, 0.2$ $352 \mathrm{~K}$ and $0.3 \mathrm{~K}$, respectively, in both channels. 
353

354 To assess the general applicability of the quadratic SW equation to different

355 atmospheric conditions, the accuracy of Eq. (13) was also evaluated using

356 another set of data, TIGR_23. Figure 13 presents the error distribution between

357 the true and the estimated SSTs, with RMSE $=0.3 \mathrm{~K}$ and bias $=0 \mathrm{~K}$.

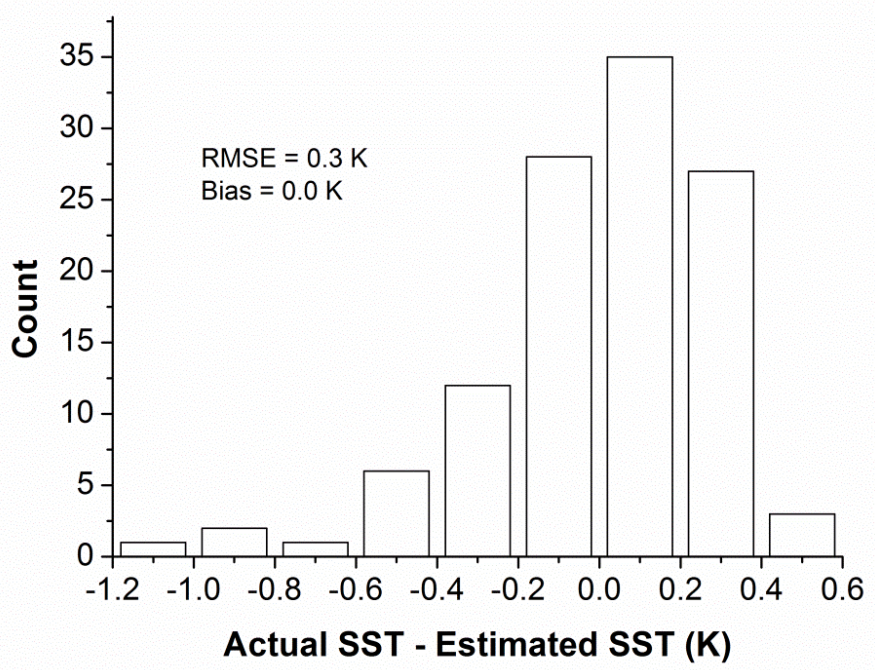

359 Figure 13. Histogram of the differences between the true and estimated SSTs 360 based on TIGR_23 data.

\section{$361 \quad 4.3$ Validation using Matchup dataset}

\subsubsection{Data processing}

363 The invalid values in MDS were first cleaned out. Considering that MSI 364 instrument observes the earth almost at nadir, the data within the VZA of $20^{\circ}$, 365 which contains 24231 pairs of in situ SSTs and AVHRR at-sensor brightness 366 temperatures matchup data, was used in this study. In order to get the "true" 
367 GF-5/MSI brightness temperatures, the relationship between GF-5/MSI and

368 AVHRR brightness temperatures was established using the simulated data for 369 each SW channel, as presented in Figure 14. It can be seen that there is a strong 370 linear relationship between GF-5/MSI and AVHRR brightness temperatures 371 with the RMSE no higher than $0.05 \mathrm{~K}$ for both channels. Using this relationship, 372 the "real" GF-5/MSI at-sensor brightness temperatures can be calculated from 373 AVHRR brightness temperatures in MDS. 24231 pairs of in situ SSTs and 374 coincident in time and space GF-5/MSI brightness temperatures were then 375 established. It should be noted that simulations may be significantly biased with 376 respected to observations due to modeling errors and not fully accuracy 377 atmospheric profiles. Observed data is also affected by uncertainties in 378 calibration, spectral response functions and residual cloud. Therefore, the 379 algorithm coefficients based on the observed data is needed to retrieve SST 380 from GF-5 satellite data. Among 24231 pairs of in situ SSTs and GF-5/MSI 381 brightness temperatures matchup data, 10000 pairs were used to obtain the 382 algorithm coefficients suitable for GF-5/MSI data, while the remaining 14231 383 pairs were used for validation purpose. According to the Figure 15, which 384 presents the quadratic relationship between buoy SSTs and GF-5/MSI 385 brightness temperatures, the coefficients $A=0.1877, B=1.845$ and $C=1.07$ in 386 the quadratic SW algorithm were obtained for GF-5/MSI data, with the RMSE $387=0.52 \mathrm{~K}$. 
388

389

390

391

392

393

394 395
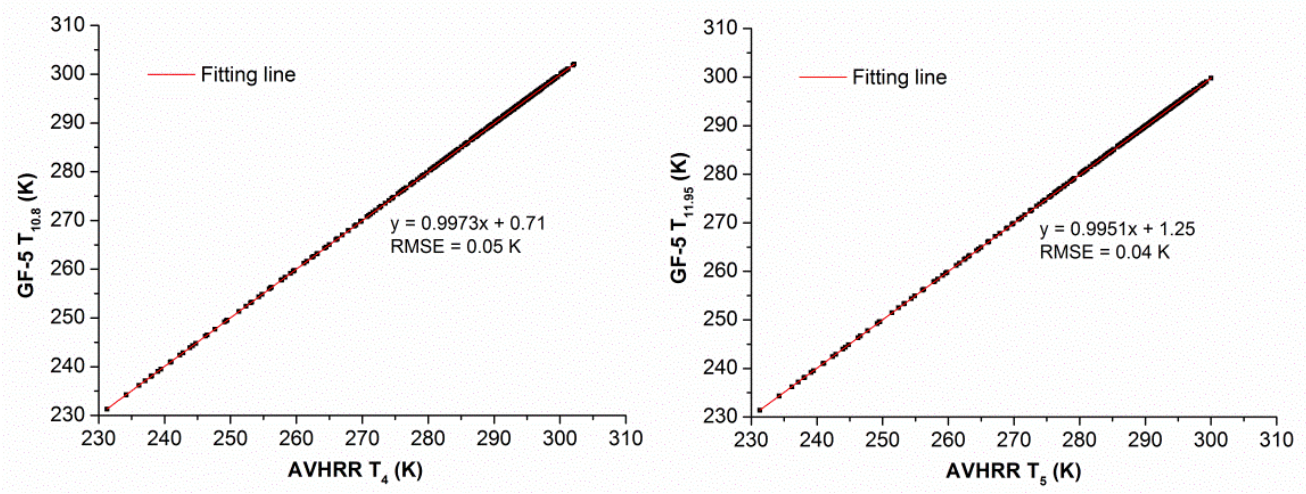

Figure 14. Plot of the simulated AVHRR and GF-5/MSI brightness temperatures for each of split-window channel.

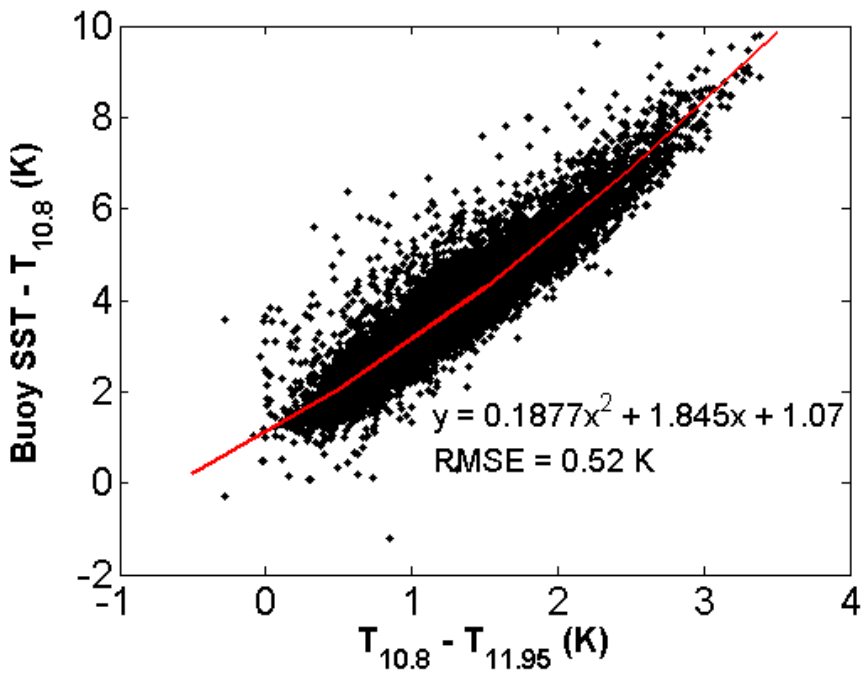

Figure 15. Plot of (Buoy SST - $\left.\mathrm{T}_{10.8}\right)$ and $\left(\mathrm{T}_{10.8}-\mathrm{T}_{11.95}\right)$. Here, Buoy SST is the sea surface temperature measured by drifting buoy, $\mathrm{T}_{10.8}$ and $\mathrm{T}_{11.95}$ are the GF5/MSI brightness temperatures calculated from AVHRR brightness temperatures in MDS.

\subsubsection{Validation results}

Using the coefficients given in Section 4.3.1, SSTs were calculated from the remaining GF-5/MSI data. Analyzing comparisons of GF-5/MSI SSTs with 

and GF-5/MSI SSTs are within $\pm 1 \mathrm{~K}$. From Figure 16, one may note that, there

402 is a large error up to about $8 \mathrm{~K}$. This may be related to the contribution of some 403 materials floating on ocean or the incorrect measurement by accidental.

404

405

406

407 408 409 410 411 412 413

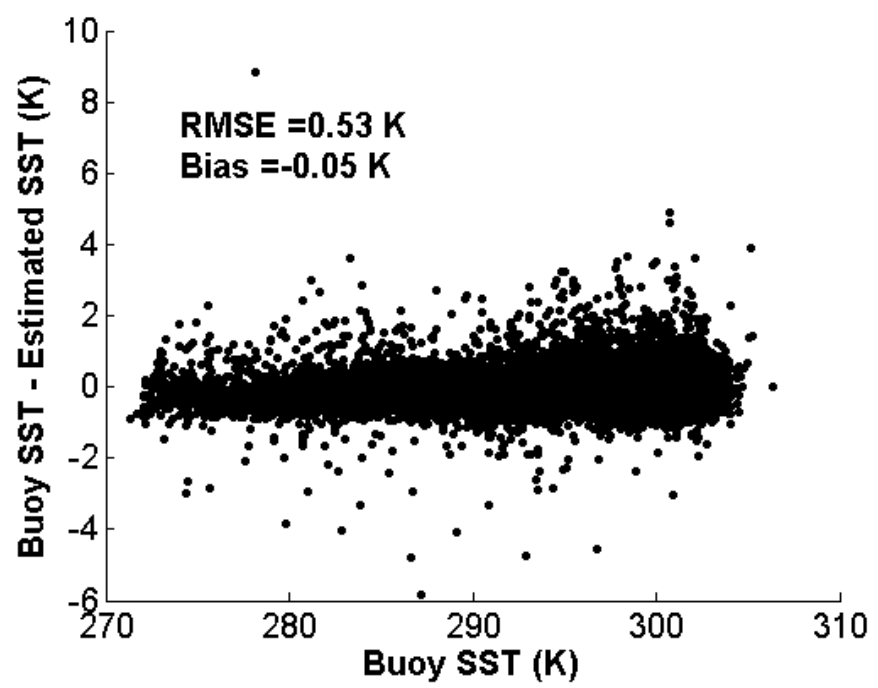

Figure 16. Buoy sea surface temperature minus sea surface temperature obtained by GF-5/MSI.

\section{Discussion}

Although many studies report the quadratic SW algorithm, this study aims for a well understanding of the semi-empirical quadratic SW algorithm. The analyses were based on a comprehension of the derivation procedure of the linear SW equation. The SST errors resulted from the linearization of the Planck function were $\mathrm{RMSE}=0.10 \mathrm{~K}$ and bias $=-0.06 \mathrm{~K}$, while the ones from the hypothesis of $T_{a i}=T_{a j}$ were $1.74 \mathrm{~K}$ and $-0.88 \mathrm{~K}$. Although the influence of the 
414 linearization of the Planck function on SST retrieval was not obvious as the

415 effect of the $T_{a i}=T_{a j}$ hypothesis, in order to interpret the physical derivation of

416 the quadratic SW algorithm, the second-order derivative of Taylor's expansion

417 of the Planck function and the linear dependence between atmospheric

418 equivalent temperatures in two SW channels were considered. The obtained

419 nonlinear SW algorithm by combining the two revisions of the Planck function

420 linearization and of the $T_{a i}=T_{a j}$ hypothesis is complex. However, it can be

421 simplified to the quadratic structure of $\left(T_{i}-T_{j}\right)$, meaning that the nonlinear $\mathrm{SW}$

422 algorithm is equivalent to the quadratic SW equation. Compared with the

423 previous studies, which presented the quadratic relationship between TOA

424 brightness temperatures and the surface temperature by maintaining the

425 structure of linear SW algorithm but no physical interpretation, this study

426 makes the physical interpretation of the semi-empirical quadratic SW algorithm

427 clear theoretically and improves our understanding of the quadratic SW

428 algorithm.

\section{6. Conclusions}

430 Some assumptions and approximations were used in the derivation of the linear

431 SW equation. Using the simulated data, this work carefully evaluated these

432 assumptions and approximations based on the RTE. We found that these

433 assumptions and approximations were not precise for SST retrieval. Therefore,

434 the revised equations for the Planck function linearization and for the 
435 relationship between the atmospheric equivalent temperatures in SW channels

436 of GF-5 data were created. Based on these studies, a nonlinear SW algorithm

437 was obtained. Further analysis of the nonlinear SW algorithm clarified that it is

438 equivalent to the quadratic SW equation but highlights the theoretical 439 interpretation.

440 The effects of instrument noise on SST retrieval using the developed 441 quadratic SW algorithm were analyzed. The total errors were $0.49 \mathrm{~K}, 0.82 \mathrm{~K}$ 442 and $1.20 \mathrm{~K}$ for NE$\Delta$ Ts of $0.1 \mathrm{~K}, 0.2 \mathrm{~K}$ and $0.3 \mathrm{~K}$, respectively. The validation 443 using the MDS produced by EUMETSAT OSI-SAF presented a RMSE of 0.53 $444 \mathrm{~K}$ and a bias of $-0.05 \mathrm{~K}$.

445 A GF-5 satellite carrying a MSI instrument with narrow swaths and a 446 high resolution of 40 meters is scheduled to be launched in 2017. The analysis 447 of GF-5 satellite data will be performed in future work when the data is 448 available. Because land surface is much more complicated than sea surface and 449 the LST differs significantly from the air temperature near the surface, large 450 errors may be introduced by the assumptions and approximations used in the 451 derivation of the linear SW method. This hypothesis will be tested in future 452 work.

\section{$453 \quad$ Funding}

454 National high-resolution earth observation project (11-Y20A32-9001-15/17). 
455

456

457

458

459

460

461

462

463

464

465

466

467

468

469

470

471

472

473

474

475

476

477

478

479

480

481

482

483

484

485

486

487

488

489

490

491

\section{Acknowledgments}

Thanks are given to Professor Christopher Merchant in the University of

Reading, who provided the MDS.

\section{References}

Anding, D., and R. Kauth. 1970. "Estimation of sea surface temperature from space." Remote Sensing of Environment 1:217-20.

Barnett, T. P., N. Graham, S. Pazan, W. White, M. Latif, and M. Flügel. 1993. "ENSO and ENSO-related predictability. Part I: Prediction of equatorial pacific sea surface temperature with a hybrid coupled ocean-atmosphere model." Journal of Climate 6:1545-66.

Barton, I. J. 1983. "Dual channel satellite measurements of sea surface temperature." Quarterly Journal of the Royal Meteorological Society 109 (460):365-78.

Barton, Ian J. 1995. "Satellite-derived sea surface temperatures: Current status." Journal of Geophysical Research 100 (C5):8777-90. doi: 10.1029/95jc00365.

Becker, F. 1987. "The impact of spectral emissivity on the measurement of land surface temperature from a satellite." International Journal of Remote Sensing 8 (10):1509-22. doi: 10.1080/01431168708954793.

Becker, FranÇOis, and Zhao-Liang Li. 1990. "Towards a local split window method over land surfaces." International Journal of Remote Sensing 11 (3):369-93. doi: 10.1080/01431169008955028.

Berk, A., G.P. Anderson, P.K. Acharya, J.H. Chetwynd, L.S. Bernstein, E.P. Shettle, M.W. Matthew, and S.M. Adler-Golden. 1999. "MODTRAN 4 user's manual." MA: Air Force Reserach Laboratory, Hanscom AFB.

Chédin, A., N.A. Scott, C. Wahiche, and P. Moulinier. 1985. "The improved initialization inversion method: A high resolution physical method for temperature retrievals from satellites of the TIROS-N series." Journal of Climate and Applied Meteorology 24:128-43.

Chelton, Dudley B., and Frank J. Wentz. 2005. "Global microwave satellite observations of sea surface temperature for numerical weather prediction and climate research." Bulletin of the American Meteorological Society 86 (8):1097-115. doi: 10.1175/bams-86-81097.

Coll, César, and Vicente Caselles. 1997. "A split-window algorithm for land surface temperature from advanced very high resolution radiometer data: Validation and algorithm comparison." Journal of Geophysical 
Research: Atmospheres 102

(D14):16697-713. doi: 10.1029/97jd00929.

Coll, C., and V. Caselles. 1994. "Analysis of the atmospheric and emissivity influence on the splitwindow equation for sea surface temperature." International journal of remote sensing 15 (9):1915-32. doi: 10.1080/01431169408954216.

Coll, C., V. Caselles, J. A. Sobrino, and E. Valor. 1994. "On the atmospheric dependence of the split-window equation for land surface temperature." International Journal of Remote Sensing 15 (1):105-22. doi: 10.1080/01431169408954054.

Donlon, C., N. Rayner, I. Robinson, D. J. S. Poulter, K. S. Casey, J. VazquezCuervo, E. Armstrong, et al. 2007. "The global ocean data assimilation experiment high-resolution sea surface temperature pilot project." Bulletin of the American Meteorological Society 88 (8):1197-213. doi: 10.1175/bams-88-8-1197.

Fisher, Edwin L. 1958. "The exchange of energy between the sea and the atmosphere in relation to hurriacne behavior." Journal of Meteorology 15:164-71.

Franqois, C., and C. Ottlé. 1996. "Atmospheric corrections in the thermal infrared: Global and water vapor dependent split-window algorithmsApplications to ATSR and AVHRR data." IEEE Transactions on Geoscience and Remote Sensing 34 (2):457-70.

Kilpatrick, K. A., G. P. Podestfi, and R. Evans. 2001. "Overview of the NOAA/NASA advanced very high resolution radiometer Pathfinder algorithm for sea surface temperature and associated matchup database." Journal of Geophysical Research 106 (C5):9179-97.

Liu, Yang, and Peter J. Minnett. 2015. "Evidence linking satellite-derived seasurface temperature signals to changes in the Atlantic meridional overturning circulation." Remote Sensing of Environment 169:150-62. doi: 10.1016/j.rse.2015.08.014.

Liu, Z.-L., H. Wu, B.-H. Tang, S. Qiu, and Z.-L. Li. 2013. "Atmospheric corrections of passive microwave data for estimating land surface temperature." Optics express 21 (13):15654-63. doi: 10.1364/OE.21.015654.

McClain, E. Paul, William G. Pichel, and Charles C. Walton. 1985. "Comparative performance of AVHRR-based multichannel sea surface temperatures." Journal of Geophysical Research 90 (C6):11587. doi: 10.1029/JC090iC06p11587.

McMillin, L.M. . 1975. "Estimation of sea surface temperature from two infrared window measurements with different absorption." Journal of Geophysical Research 80 (36):5113-7.

Niclòs, Raquel, Vicente Caselles, César Coll, and Enric Valor. 2007. "Determination of sea surface temperature at large observation angles 
using an angular and emissivity-dependent split-window equation." Remote Sensing of Environment 111 (1):107-21. doi: 10.1016/j.rse.2007.03.014.

Petrenko, Boris, Alexander Ignatov, Yury Kihai, John Stroup, and Prasanjit Dash. 2014. "Evaluation and selection of SST regression algorithms for JPSS VIIRS." Journal of Geophysical Research: Atmospheres 119 (8):4580-99. doi: 10.1002/2013jd020637.

Pinardi, N., I. Allen, E. Demirov, P. De Mey, G. Korres, A. Lascaratos, P.-Y. Le Traon, C. Maillard, G. Manzella, and C. Tziavos. 2003. "The Mediterranean ocean forecasting system first phase of implementation (1998-2001)." Annales Geophysicae 21 (1):3-20.

Prabhakara, C., G. Dalu, and V.G. Kunde. 1974. "Estimation of sea surface temperature from remote sensing in the $11-13 \mu \mathrm{m}$ window region." Journal of Geophysical Research 79:5039-44.

Qian, Y.-G., N. Wang, L.-L. Ma, Y.-K. Liu, H. Wu, B.-H. Tang, L.-L. Tang, and C.-R. Li. 2016. "Land surface temperature retrieved from airborne multispectral scanner mid-infrared and thermal-infrared data." Optics express 24 (2):A257-69. doi: 10.1364/OE.24.00A257.

Rozenstein, O., Z. Qin, Y. Derimian, and A. Karnieli. 2014. "Derivation of land surface temperature for Landsat-8 TIRS using a split window algorithm." Sensors (Basel) 14 (4):5768-80. doi: 10.3390/s140405768.

Scott, N.A., and A. Chédin. 1981. "A fast line-by-line method for atmospheric absorption computations: The Automatized Atmospheric Absorption Atlas." Journal of Applied Meteorology 20:802-12.

Simpson, James J. 1994. "Remote sensing in fisheries: A tool for better management in the utilization of a renewable resource." Canadian Journal of Fisheries and Aquatic Sciences 51:743-71.

Sobrino, J.A., C. Coll, and V. Caselles. 1991. "Atmospheric corrections for land surface temperature using AVHRR channels 4 and 5." Remote Sensing of Environment 38:19-34.

Sobrino, José A., Zhao-Liang Li, and Marc P. Stoll. 1993. "Impact of the atmospheric transmittance and total water vapor content in the algorithms for estimating satellite sea surface temperatures." IEEE Transactions on Geoscience and Remote Sensing 31 (5):946-52.

Ulivieri, C., M. M. Castronuovo, R. Francioni, and A. CardiUo. 1994. "A split window algorithm for estimating land surface temperature from satellites." Advances in Space Research 14 (3):59-65.

Walton, C. C., W. G. Pichel, J. F. Sapper, and D. A. May. 1998. "The development and operational application of nonlinear algorithms for the measurement of sea surface temperatures with the NOAA polarorbiting environmental satellites." Journal of Geophysical Research: Oceans 103 (C12):27999-8012. doi: 10.1029/98jc02370. 